\title{
The Human Error Research of Human-Computer Interaction VDT Continuous Operating Based on Experiment
}

\author{
Huimin Teng, ${ }^{1, a}$, Bin Liao ${ }^{1, b}$, Junhao Luo ${ }^{1, c}$ and Kailun Yue ${ }^{1, d}$ \\ ${ }^{1}$ School of Business, Sichuan Normal University, Chengdu, China \\ a819122224@qq.com, b451079682@qq.com, ㄷ49156641@qq.com, ${ }^{\mathrm{d}}$ 1096332008@qq.com
}

\begin{abstract}
Keywords: Human reliability, Human error, VDT operation, Experiment, Variance analysis.
Abstract. In this paper, by simulating actual operation, detailed study of human-computer interaction in continuous VDT operation the effects of five factors on two types of human error and their extent of the impact. The five factors: sex workers, a different color, different task difficulty, different way of expressing information, with or without a time limit. The two types of human error: wrong operation and timeout errors. The results show that five factors influence on timeout errors is not obvious. Impact on wrong operation is significant: color interface error rate is lower than the black, the female error rate is lower than that of the male, and the error rate in the simple task is lower than that in the complex. The influence of five factors on the error rate is from large to small is: task difficulty, time limit and sex workers, expressing information, color.
\end{abstract}

\section{Introduction}

VDT (Visual Display Terminal) operation is the generic term by using personal computers, computer systems, and visual display terminal to handle data, text, images and other information processing jobs. VDT operation, with the popularity of computers, has become a representative of modern labor[1]. Studies of VDT operation in China started relatively late mostly in 1980s. And published articles about VDT operation in the academic journals in China, the experimental research papers accounted for only about $7 \%$. So the researches of VDT operation in China are still in the early stage of the investigation and study[2].

Referring to the relevant literature, human error is the most important cause of VDT operation safety accidents. Shiqian Lian analyzed mechanisms of the human error and proposed prevention strategies[3].Li Zhang pointed out that human error was the key problem of the human-computer interaction[4]. There are a lot of imperfections in the development process of human error, and these are the hot topics in the current discussion.

According to J. Reason's classification of human error[5], human error in this paper was divided into two types: wrong operation and timeout errors. Wrong operation meant that the actual task result was different from the expected result; timeout errors were the task could not be completed within the specified time. Based on the simulation of the actual work, this paper got the error rate of two types of human error in the VDT operation under the five factors. The five factors: sex workers (male and female), a different color (black and color), different task difficulty (simple and complex), different way of expressing information (images and text), with or without a time limit.

\section{Methods}

Independent variables. Variables of operators: sex workers (male and female); variables of tasks: a different color (black and color), different task difficulty (simple and complex), different way of expressing information (images and text), with or without a time limit.

Dependent variables. Reaction time and correct rate. The design of experimental task group was shown in Table. 1.

Tasks. 100 questions, each of the 20 questions as a group. There were five groups, each group of questions presented in different ways, but the same task requirements. Each question had four options, the task was to select the only different option in each question. 
Table. 1. The design of experimental task group

\begin{tabular}{cccccc}
\hline Task groups & $\begin{array}{c}\text { Amount of } \\
\text { questions }\end{array}$ & Different color & $\begin{array}{c}\text { Way of expressing } \\
\text { information }\end{array}$ & $\begin{array}{c}\text { Task } \\
\text { difficulty }\end{array}$ & Time limit \\
\hline 1 & $1 \sim 20$ & black & image & simple & 0 \\
2 & $21 \sim 40$ & color & image & simple & 0 \\
3 & $41 \sim 60$ & black & image & complex & 0 \\
4 & $61 \sim 80$ & black & text & simple & 0 \\
5 & $81 \sim 100$ & black & text & simple & $6000 \mathrm{~ms}$ \\
\hline
\end{tabular}

Design and procedure. The E-prime1.1 software was used to write the control experiment tasks; the experiment was divided into two different kinds of time limits. In this paper, two different types of experimental materials and the relevant control of List and the different core experimental processes of CEP were constructed to form a parallel relationship. The first core experiment contained the first four task groups, each of which trail started from the middle of the screen prompt "+". After $800 \mathrm{ms,}$ the experimental tasks were presented including subject requirements and four options. Subjects were asked to press the keyboard to represent the different options on the number of keys "1", "2", "3", "4". There was no restriction on the time of each task; the second core experiment contained only the fifth task group, the only difference was that each task had a time limit to $6000 \mathrm{~ms}$. In order to distinguish between wrong operation and timeout errors, the participants were told that the total time of the first four groups was limited to 10 minutes.

Participants. In all, one hundred participants were recruited from the Sichuan Normal University, China. They were undergraduate students with a mean age of 18 to 26 years old. There were 41 males and 59 females, participants were healthy, no color blindness. They had no history of doing similar experiments that would affect this experiment.

Apparatus. Lenovo notebook computer, the screen was 14 inches widescreen LCD display, the resolution was $1366 * 768$.

Analysis. The reaction time and correct rate were processed by EXCEL software and SPSS software. The differences in conditions of five factors were analyzed using a repeated-measure analysis of variance (RANOVA) test and pairwise comparison Post Hoc tests (Tukey HSD). Statistical significances in all analyses were assumed to be less than 5 percent $(p<0.05)$.

\section{Results}

The difference of experience and knowledge between every operator leads to a different reaction time, hence leading to a timeout error. In this paper, the principle that the reaction time is a timed out: reaction time is greater than the sum of the mean and standard deviation. The correct rate reflects the error rate indirectly. Since the types of human error are divided into two types: wrong operation and timeout errors. The discussion of correct rate is divided into two categories: the correct rate in the case of wrong operation and the correct rate in case of timeout errors. In order to facilitate the experimental comparison, this paper reorganizes five task groups into five variable groups, as shown in Table. 2.

\section{Comparison in the group.}

In the case of wrong operation. Table. 3 shows that the factors of group A, group B, group C and group $\mathrm{D}$ have significant effects on the correct rate of wrong operation $(\mathrm{P}<0.01)$. Table. 4 shows the mean correct rate between different group: group $2>$ group 1, group $1>$ group 3, group $1>$ group 4 , group $4>5$. Accordingly, the influence of the four factors (task difficulty, time limit, the way of expressing information, color) on the error rate in the wrong operation is extremely significant. And the error rate in the color interface is lower than in the black interface; the error rate in the simple tasks is lower than in the complex tasks; the error rate is lower when the information is image than the information is text; when time is unlimited, the error rate is lower.

In the case of timeout errors. Since group 5 is time-limited, it cannot clearly distinguish the correct rate of wrong operation and the correct rate of timeout. There is no point in discussing the correct rate of timeout, so the fifth group is only used to discuss the correct rate of wrong operation. 
Table. 3 shows that factors of group A, group B and group $\mathrm{C}$ have no significant effect on the correct rate of timeout $(\mathrm{P}>0.05)$. Accordingly, the effect of three factors (task difficulty, expressing information, color) on the error rate of timeout is not significant, so there is no longer analyzed.

Table. 2. The experimental variable group

\begin{tabular}{ccc}
\hline $\begin{array}{c}\text { Variable } \\
\text { groups }\end{array}$ & Composition & Independent variable \\
\hline A & $1-2$ & color \\
B & $1-3$ & task difficulty \\
C & $1-4$ & expressing information \\
D & $4-5$ & time limit \\
E & Female - male & sex workers \\
\hline
\end{tabular}

Table. 4. Means of correct rate

\begin{tabular}{ccc}
\hline $\begin{array}{c}\text { Task } \\
\text { groups }\end{array}$ & $\begin{array}{c}\text { Mean(wrong } \\
\text { operation) }\end{array}$ & $\begin{array}{c}\text { Mean(timeout } \\
\text { errors) }\end{array}$ \\
\hline 1 & 0.891 & 0.851 \\
2 & 0.958 & 0.854 \\
3 & 0.449 & 0.837 \\
4 & 0.828 & 0.850 \\
5 & 0.747 & 0.851 \\
\hline
\end{tabular}

Table. 6. Means of correct rate

\begin{tabular}{cccc}
\hline $\begin{array}{c}\text { Variable } \\
\text { groups }\end{array}$ & Sex & $\begin{array}{c}\text { Task } \\
\text { groups }\end{array}$ & $\begin{array}{c}\text { Mean(wrong } \\
\text { operation) }\end{array}$ \\
\hline & & 1 & 0.868 \\
& male & 2 & 0.935 \\
& & Total & 0.902 \\
& female & 1 & 0.907 \\
& & 2 & 0.973 \\
& & 1 & 0.940 \\
& Total & 0.868 \\
C & & 4 & 0.805 \\
& & Total & 0.837 \\
& female & 4 & 0.907 \\
& & Total & 0.843 \\
\hline
\end{tabular}

Table. 9. Means of correct rate

\begin{tabular}{ccc}
\hline $\begin{array}{c}\text { Variable } \\
\text { groups }\end{array}$ & $\begin{array}{c}\text { Mean(wrong } \\
\text { operation) }\end{array}$ & $\begin{array}{c}\text { Mean(timeout } \\
\text { errors) }\end{array}$ \\
\hline A & 0.924 & 0.924 \\
B & 0.670 & 0.670 \\
C & 0.859 & 0.859 \\
D & 0.787 & \\
E & 0.774 & 0.774 \\
\hline
\end{tabular}

Table. 3. Significance test-in the group

\begin{tabular}{ccc}
\hline Variable & \multicolumn{2}{c}{$p$ Value } \\
\cline { 2 - 3 } groups & Wrong operation & Timeout errors \\
\hline $\mathrm{A}$ & .000 & 0.705 \\
$\mathrm{~B}$ & .000 & 0.066 \\
$\mathrm{C}$ & .000 & 0.895 \\
$\mathrm{D}$ & .000 & \\
\hline Table.5. Significance test-sex workers \\
\hline Variable & \multicolumn{2}{c}{$p$ Value } \\
groups & Wrong operation & Timeout errors \\
\hline $\mathrm{A}$ & 0.003 & 0.674 \\
$\mathrm{~B}$ & 0.269 & 0.396 \\
$\mathrm{C}$ & 0.007 & 0.689 \\
$\mathrm{D}$ & 0.628 & \\
\hline
\end{tabular}

Table. 7. Significance test-between groups

\begin{tabular}{ccc}
\hline Variable & \multicolumn{2}{c}{$p$ Value } \\
\cline { 2 - 3 } groups & Wrong operation & Timeout errors \\
\hline A、B、C、 & .000 & .000 \\
\hline
\end{tabular}

Table. 8. Multiple comparisons

\begin{tabular}{cccc}
\hline \multirow{2}{*}{$\begin{array}{c}\text { Variable } \\
\text { groups }\end{array}$} & $\begin{array}{c}(\mathrm{J}) \\
\text { Variable } \\
\text { groups }\end{array}$ & \multicolumn{2}{c}{$p$ Value } \\
\cline { 3 - 4 } & $\begin{array}{c}\text { Wrong } \\
\text { operation }\end{array}$ & $\begin{array}{c}\text { Timeout } \\
\text { errors }\end{array}$ \\
\hline & $\mathrm{B}$ & .000 & .000 \\
$\mathrm{~A}$ & $\mathrm{C}$ & .000 & .000 \\
& $\mathrm{D}$ & .000 & \\
& $\mathrm{E}$ & .000 & .000 \\
$\mathrm{~B}$ & $\mathrm{~A}$ & .000 & .000 \\
& $\mathrm{C}$ & .000 & .000 \\
& $\mathrm{D}$ & .000 & \\
& $\mathrm{E}$ & .000 & .000 \\
$\mathrm{C}$ & $\mathrm{A}$ & .000 & .000 \\
& $\mathrm{~B}$ & .000 & .000 \\
& $\mathrm{D}$ & .000 & \\
& $\mathrm{E}$ & .000 & .000 \\
$\mathrm{D}$ & $\mathrm{A}$ & .000 & .000 \\
& $\mathrm{~B}$ & .000 & .000 \\
& $\mathrm{C}$ & .000 & \\
& $\mathrm{E}$ & 0.964 & .000 \\
$\mathrm{E}$ & $\mathrm{A}$ & .000 & .000 \\
& $\mathrm{~B}$ & .000 & .000 \\
& $\mathrm{C}$ & .000 & .000 \\
& $\mathrm{D}$ & 0.964 & \\
\hline
\end{tabular}

For gender. Table. 5 shows that the correct rate of sex workers on error operation is significant only in group A and group $\mathrm{C}(\mathrm{P}<0.05)$, But there is no significant difference in the correct rate of timeout among groups $\mathrm{A}, \mathrm{B}$ and $\mathrm{C}(\mathrm{P}>0.05)$. Table. 6 shows that the correct rate of wrong operation in the group $\mathrm{A}$ and $\mathrm{C}$ is higher in female than in male $(0.940>0.902 ; 0.875>0.837)$, and the mean correct: group $2>$ group 1, group $1>$ group 4 . Accordingly, the influence of sex workers on the error rate of wrong operation is significant under different color interface, and the error rate in color interface is lower than that in black interface $(0.935>0.868 ; 0.973>0.907)$. In different ways of 
expressing information, the influence of sex workers on the error rate of wrong operation is significant. And the error rate is lower when the information is image than the information is text $(0.868>0.805 ; 0.907>0.843)$, the error rate of female is lower than that of male $(0.907>0.868$; $0.973>0.935 ; 0.907>0.868 ; 0.843>0.805)$.

\section{Comparison between groups.}

In the case of wrong operation. Table. 7 shows that there is a extremely significant difference between the five groups in the correct rate $(\mathrm{P}<0.01)$. Table. 8 shows that there is no significant difference between the group $\mathrm{D}$ and the group $\mathrm{E}$, there is a significant difference between the other groups. In Table.9, the mean of the correct rate from large to small is: group A, group C, group D, group E, group B, and the data of group D and group E are very similar. The results show that the five factors have a significant effect on the error rate of wrong operation, and the influence from large to small is: task difficulty, time limit and sex workers, expressing information, color.

In the case of timeout errors. Table. 7 shows that there is a extremely significant difference between the four groups in the correct rate $(\mathrm{P}<0.01)$. Table. 8 shows that there is a significant difference between the four groups. In Table. 9, the mean of the correct rate from large to small is: group A, group C, group E, group B. The results show that the four factors have a significant effect on the error rate of timeout errors, and the influence from large to small is: task difficulty, sex workers, expressing information, color.

\section{Conclusions}

In VDT continuous operation, the impact of five factors on the timeout errors is not obvious, but the impact on wrong operation is significant. The task difficulty has the greatest influence on the error rate, the more difficulty of the task leads to the higher error rate. The secondly factors are the sex workers and time limit: error rate of female workers is lower than that of male workers; the larger the time limit, the lower the error rate. The third factor is different way of expressing information, the error rate of images task compared to the text task is lower. The fourth factor is color, the error rate decreases with the increase of the number of colors. Finally, in order to reduce the rate of human error, and ensure the safety of VDT operations. This paper presents some suggestions:

In the tasks. The task interface is designed to colorful pictures or illustrations in the form of easy to understand; the task is marked with some hints to make the task more logical and simple; as far as possible to give sufficient time to ensure that the cognition of the operators to the task.

In the operators. Testing the operators and assigning jobs based on the strengths and weaknesses; training the operators and strengthening exercises to achieve proficiency in the content of the work; developing reward system to improve the enthusiasm of the operators.

\section{Acknowledgements}

This work was financially supported by the MOE (Ministry of Education in China) Youth Project of Humanities and Social Sciences (14YJCZH089), the Social Science Foundation of Sichuan Province of China (SC16B065) and Sichuan Province Undergraduate Training Program for Innovation and Entrepreneurship (201610636145).

\section{Reference}

[1] Ligang Gu, Furong Han. Industrial Engineering Journal in Chinese Vol. 2 (2003), p. 10-13.

[2] Ligang Gu. Study on VDT work and its management. Huazhong University of Science and Technology (2004).

[3] Shiqian Lian, Li Zhang, Yiqun Wang, Hongtao Song. Journal of University of South China (Social Science Edition) in Chinese Vol. 8 (2007), p. 46-49. 
[4] Li Zhang, Yiqun Wang, Zhiliang Deng. China Safety Science Journal in Chinese Vol. 6 (1996), p. 35-38.

[5] Reason J. Human Error.UK Cambridge University Press (1990), p. 32-52, 61-65. 